\title{
Minimally invasive approach provides at least equivalent results for surgical correction of mitral regurgitation: A propensity-matched comparison
}

\author{
Andrew B. Goldstone, MD, ${ }^{\mathrm{a}}$ Pavan Atluri, MD, ${ }^{\mathrm{a}}$ Wilson Y. Szeto, MD, ${ }^{\mathrm{a}}$ Alen Trubelja, BS, ${ }^{\mathrm{a}}$

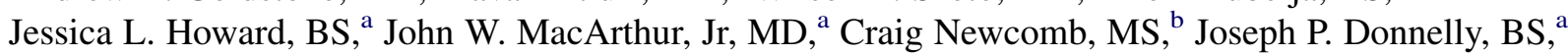 \\ Dale M. Kobrin, BA, ${ }^{a}$ Mary A. Sheridan, MPAS, PA-C, ${ }^{a}$ Christiana Powers, MSN, CRNP, ${ }^{\mathrm{a}}$

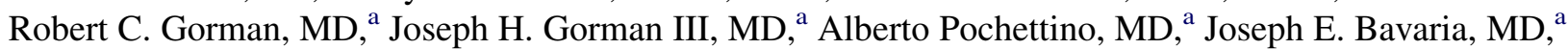 \\ Michael A. Acker, MD, ${ }^{a}$ W. Clark Hargrove III, MD, ${ }^{a}$ and Y. Joseph Woo, MD ${ }^{\mathrm{a}}$
}

\begin{abstract}
Objective: Minimally invasive approaches to mitral valve surgery are increasingly used, but the surgical approach must not compromise the clinical outcome for improved cosmesis. We examined the outcomes of mitral repair performed through right minithoracotomy or median sternotomy.
\end{abstract}

\begin{abstract}
Methods: Between January 2002 and October 2011, 1011 isolated mitral valve repairs were performed in the University of Pennsylvania health system (455 sternotomies, 556 right minithoracotomies). To account for key differences in preoperative risk profiles, propensity scores identified 201 well-matched patient pairs with mitral regurgitation of any cause and 153 pairs with myxomatous disease.
\end{abstract}

\begin{abstract}
Results: In-hospital mortality was similar between propensity-matched groups ( $0 \%$ vs $0 \%$ for the degenerative cohort; $0 \%$ vs $0.5 \%, P=.5$ for the overall cohort; in minimally invasive and sternotomy groups, respectively). Incidence of stroke, infection, myocardial infarction, exploration for postoperative hemorrhage, renal failure, and atrial fibrillation also were comparable. Transfusion was less frequent in the minimally invasive groups ( $11.8 \%$ vs $20.3 \%, P=.04$ for the degenerative cohort; $14.0 \%$ vs $22.9 \%, P=.03$ for the overall cohort), but time to extubation and discharge was similar. A $99 \%$ repair rate was achieved in patients with myxomatous disease, and a minimally invasive approach did not significantly increase the likelihood of a failed repair resulting in mitral valve replacement. Patients undergoing minimally invasive mitral repair were more likely to have no residual post-repair mitral regurgitation $(97.4 \%$ vs $92.1 \%, P=.04$ for the degenerative cohort; $95.5 \%$ vs $89.6 \%, P=.02$ for the overall cohort). In the overall matched cohort, early readmission rates were higher in patients undergoing sternotomies $(12.6 \%$ vs $4.4 \%, P=.01)$. Over 9 years of follow-up, there was no significant difference in long-term survival between groups $(P=.8)$.
\end{abstract}

Conclusions: In appropriate patients with isolated mitral valve disease of any cause, a right minithoracotomy approach may be used without compromising clinical outcome. (J Thorac Cardiovasc Surg 2013;145:748-56)

During the past 20 years, the increasing popularity of lessinvasive procedures has affected nearly every surgical specialty, including cardiac surgery. Advancements in imaging, surgical instrumentation, and robotic technology have enabled surgeons to perform complex cardiac surgical procedures through small incisions, often eliminating the need for

\footnotetext{
From the Department of Surgery, ${ }^{\text {a }}$ Division of Cardiovascular Surgery, Perelman School of Medicine, University of Pennsylvania, Philadelphia, Pa; and Department of Biostatistics and Epidemiology, ${ }^{\mathrm{b}}$ Center for Clinical Epidemiology and Biostatistics, University of Pennsylvania, Philadelphia, Pa.

Disclosures: Authors have nothing to disclose with regard to commercial support.

Read at the 38th Annual Meeting of The Western Thoracic Surgical Association, Maui, Hawaii, June 27-30, 2012.

Received for publication June 25, 2012; revisions received Aug 22, 2012; accepted for publication Sept 12, 2012.

Address for reprints: Y. Joseph Woo, MD, Associate Professor of Surgery, Division of Cardiovascular Surgery, Department of Surgery, University of Pennsylvania, Silverstein 6, 3400 Spruce St, Philadelphia, PA 19104 (E-mail: wooy@uphs. upenn.edu)

0022-5223/\$36.00

Copyright (c) 2013 by The American Association for Thoracic Surgery

http://dx.doi.org/10.1016/j.jtcvs.2012.09.093
}

sternotomy or cardiopulmonary bypass. ${ }^{1-4}$ In addition to benefits of improved cosmesis, minimally invasive mitral valve surgery was pioneered with the intent of reducing morbidity, postoperative pain, blood loss, hospital length of stay, and time to return to normal activity. ${ }^{5,6}$ Although clinical studies support many of the theoretical advantages of less-invasive approaches to mitral valve surgery, no definitive randomized trial has been conducted to date. ${ }^{6-12}$ Treatment allocation bias inherent in retrospective studies begets significant differences in baseline risk profiles of minimally invasive and sternotomy groups, often with the higher-risk patients in the sternotomy cohort. Propensity score analysis helps to control for such bias, but requires a large study population, and only a handful of such studies have been published thus far. ${ }^{13-17}$

Just as novel operative techniques have developed, the management of mitral regurgitation (MR) continues to change as our knowledge of the disease pathophysiology evolves. Treatment paradigms have shifted to identify 


\section{Abbreviation and Acronym \\ $\mathrm{MR}=$ mitral regurgitation}

patients earlier in the disease course, before the development of adverse sequelae of long-standing MR on left ventricular function and geometry. ${ }^{18}$ In the setting of degenerative mitral valve disease, there exists a growing advocacy for referral of asymptomatic patients for surgery. ${ }^{18,19}$ As minimally invasive approaches to mitral valve surgery are increasingly used, and mitral valve repair has now extended to the asymptomatic population, it is essential that the surgical approach not compromise the clinical outcome for improved cosmesis. We sought to compare the early and late outcomes of isolated mitral valve repair performed through right minithoracotomy and median sternotomy at a high-volume academic health system.

\section{MATERIALS AND METHODS Study Population}

Between January 2002 and October 2011, 4241 mitral valve operations were performed within the University of Pennsylvania Health system. The study population was limited to adult patients who underwent isolated mitral valve repair $(n=1011)$, defined as any mitral valve repair procedure performed in the absence of a major concomitant procedure (eg, coronary bypass, other valve surgery, or aortic surgery). To avoid intention-to-treat selection bias, a subgroup analysis of patients who underwent isolated mitral valve replacement $(n=272)$ during the same study period also was analyzed. Data were in part retrieved from the University of Pennsylvania's prospective Society of Thoracic Surgeon's registry and partially obtained from each patient's medical record. These data were approved for use in research by the University of Pennsylvania Institutional Review Board with a waiver of patient consent.

\section{Operative Technique}

The definition of minimally invasive mitral valve surgery is broad and generally inclusive of any operation performed through less than a conventional median sternotomy. For the purpose of the present study, this definition was narrowed to include only isolated mitral valve repairs performed through a right minithoracotomy. A conventional median sternotomy approach was used in 455 patients ( $44 \%$ ), and a minimally invasive approach was used in 556 patients $(66 \%)$. The main determinant of the surgical approach used was the preference of the patient or referring cardiologist, with absolute contraindications including only severe peripheral arterial disease and high-grade atheroma of the descending aorta.

Minimally invasive mitral valve repair was performed using standardized methods similar to those previously described. ${ }^{1,3,10,13,20}$ Briefly, standard monitoring lines are placed and the patient is intubated with a double-lumen endotracheal tube. Before draping, the right internal jugular vein is cannulated with a $16 \mathrm{~F}$ femoral cannula. Access to the thoracic cavity is achieved via a $4-\mathrm{cm}$ incision in the inframammary groove that is carried through the third or fourth intercostal space. A soft tissue retractor is used to limit rib spreading. Femoral venous cannulation is performed with a $22 \mathrm{~F}$ or $25 \mathrm{~F}$ cannula, and femoral arterial cannulation is performed with a $14 \mathrm{~F}, 16 \mathrm{~F}$, or $18 \mathrm{~F}$ cannula depending on body size, or a $21 \mathrm{~F}$ cannula with a side port if using endoaortic occlusion. The opened pericardium is retracted toward the right. Before cannulation, a complete echocardiographic assessment of the ascending aorta is performed. Cardiopulmonary bypass is initiated, and the heart is arrested with antegrade cold blood cardioplegia. When the heart is accessed through median sternotomy, myocardial protection is achieved with antegrade and retrograde cold blood cardioplegia. Use of retrograde cardioplegia during minimally invasive mitral repair depends on surgeon preference. In approximately $30 \%$ of cases, an endoaortic balloon (Edwards Lifesciences, LLC, Irvine, Calif) was used for proximal aortic occlusion. The balloon is positioned under transesophageal echocardiographic guidance just above the sinotubular junction with careful attention paid to bilateral radial artery pressures. Otherwise, central aortic cannulation was performed via the initial thoracotomy incision, and aortic occlusion was accomplished with transthoracic clamping (Chitwood clamp; Scanlan International Inc, Minneapolis, Minn). After cardiac arrest, the left atrium is entered along the interatrial groove. Mitral valve repair is performed using standardized techniques. Carbon dioxide field insufflation and standardized transesophageal echocardiography-guided de-airing techniques are routinely used to help minimize risk of air embolus. After atrial closure and separation from cardiopulmonary bypass, a complete postoperative transesophageal echocardiographic study is recorded. Postrepair echocardiographic data were obtained after incision closure.

\section{Statistical Analysis}

Continuous variables are expressed as the mean \pm standard deviation, and categorical variables are presented as proportions. Comorbid diagnoses and perioperative outcome variables adhere to the definitions of the Society of Thoracic Surgeons National Database. Differences between groups were assessed using the Fisher exact test for categorical variables, the independent Student $t$ test for normally distributed continuous variables, and the Mann-Whitney $U$ test for non-normally distributed continuous variables. Survival analyses were performed using Kaplan-Meier survival analysis with log-rank tests. All tests were 2-tailed.

The propensity to undergo minimally invasive mitral valve repair was calculated using multivariable logistic regression to model a dichotomous outcome of minimally invasive or open repair for all patients in the sample, as well as for only patients with degenerative mitral valve disease. Eleven fixed-effect variables were included in the final model (Appendices 1 and 2). Patients with similar propensity scores were matched in a 1:1 nearest neighbor fashion across the total distribution of propensity scores. Although a difference in propensity score less than 0.1 was required for a match, the majority of matches did not approach this limit (median difference, 0.0015; interquartile range, 0.0005-0.008). Matched pairs were identified across a wide range of propensity scores (Figure 1). The statistical analysis was performed using SAS for Windows (SAS Institute, Inc, Cary, NC) and IBM SPSS Statistics for Macintosh, version 19.0 (SPSS, Inc, Armonk, NY).

\section{RESULTS}

Baseline demographics and comorbidity profiles are summarized in Table 1. Patients undergoing the minimally invasive procedure were more likely to have less symptomatic MR due to degenerative mitral valve disease, as well as higher ejection fractions and less concomitant tricuspid regurgitation. Fewer patients in the minimally invasive cohort had hypertension, chronic lung disease, or endocarditis. Two separate propensity score analyses were conducted to account for differences in baseline characteristics in the study population: (1) a matched comparison of patients with mitral valve disease of any cause $(\mathrm{n}=402)$ or $(2)$ a matched comparison limited to only patients with degenerative mitral valve disease $(\mathrm{n}=306)$ (Table 2$)$. In both comparisons, matched groups were similar with regard to all preoperative comorbidity, hemodynamic, and demographic categories. 

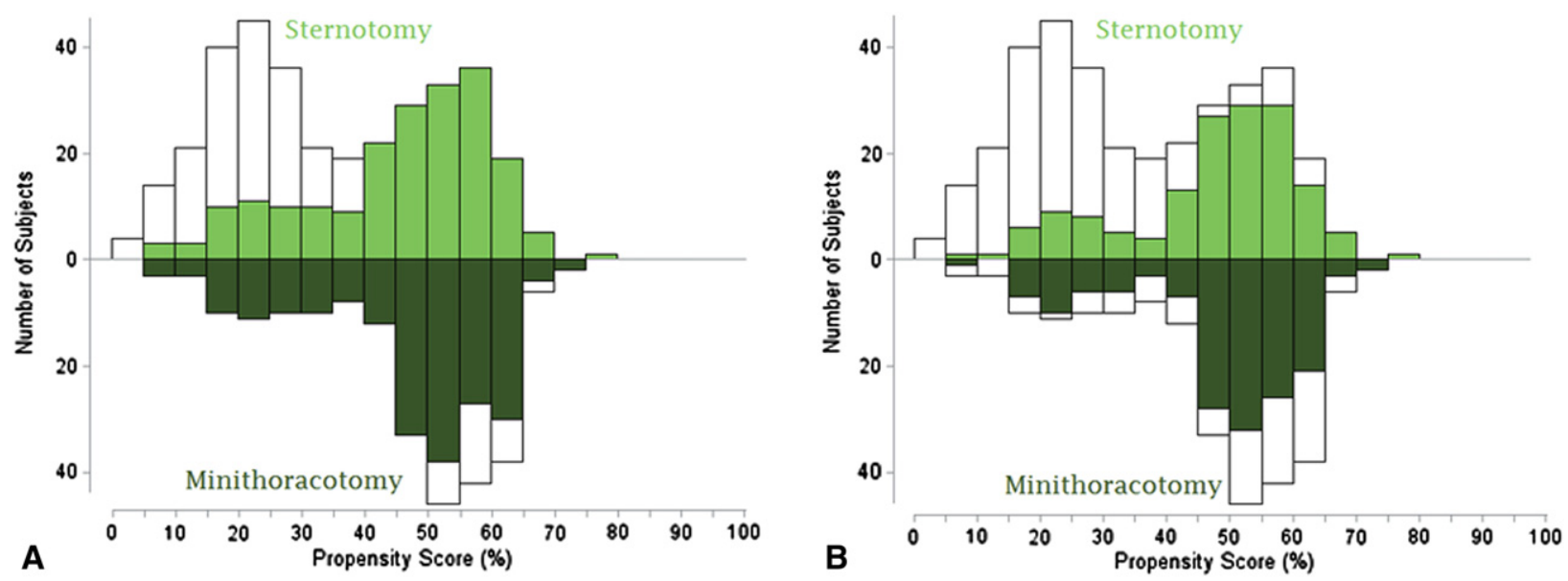

FIGURE 1. Mirrored histogram of distribution of propensity scores for sternotomy (bars above zero line) and minimally invasive (bars below zero line) approaches for overall matched cohort (A) and degenerative matched cohort (B). Green areas represent matched patient pairs and demonstrate that the sample consisted of nearly the complete spectrum of cases.

Operative data are presented in Table 3. In both matched subgroup comparisons, ischemic and cardiopulmonary bypass times were significantly longer in those undergoing the

TABLE 1. Demographics and clinical characteristics of patients undergoing mitral valve repair: Entire study population

\begin{tabular}{|c|c|c|c|}
\hline Variable & $\begin{array}{c}\text { Median } \\
\text { sternotomy } \\
(\mathbf{n}=\mathbf{4 5 5})\end{array}$ & $\begin{array}{c}\text { Minimally } \\
\text { invasive } \\
(\mathbf{n}=\mathbf{5 5 6})\end{array}$ & $\begin{array}{c}P \\
\text { value }\end{array}$ \\
\hline \multicolumn{4}{|l|}{ Demographics } \\
\hline Age (y) & $57.7 \pm 13.6$ & $57.6 \pm 12.7$ & 1.0 \\
\hline Gender ( $\%$ female $)$ & $174(38.2 \%)$ & $211(37.9 \%)$ & .9 \\
\hline BMI $\left(\mathrm{kg} / \mathrm{m}^{-2}\right)$ & $26.6 \pm 5.4$ & $26.7 \pm 7.6$ & .8 \\
\hline \multicolumn{4}{|l|}{ Comorbidities } \\
\hline Chronic kidney disease & $27(5.9 \%)$ & $20(3.6 \%)$ & .1 \\
\hline Hypertension & $233(51.3 \%)$ & $237(42.7 \%)$ & .006 \\
\hline Infective endocarditis & $42(9.3 \%)$ & $27(4.9 \%)$ & .008 \\
\hline Chronic lung disease & $58(12.8 \%)$ & $43(7.7 \%)$ & .008 \\
\hline Peripheral arterial disease & $14(3.1 \%)$ & $11(2.0 \%)$ & .3 \\
\hline Cerebrovascular disease & $37(8.2 \%)$ & $37(6.7 \%)$ & .4 \\
\hline Previous cardiac surgery & $57(12.6 \%)$ & $64(11.5 \%)$ & 6 \\
\hline NYHA functional class & & & $<.001$ \\
\hline I & $111(25.1 \%)$ & $139(25.1 \%)$ & \\
\hline II & $186(42.0 \%)$ & $304(55.0 \%)$ & \\
\hline III & $132(29.8 \%)$ & $86(15.6 \%)$ & \\
\hline IV & $14(3.2 \%)$ & $24(4.3 \%)$ & \\
\hline Cause & & & .003 \\
\hline Degenerative & $280 / 401(61.5 \%)$ & $242 / 298(81.2 \%)$ & \\
\hline Functional & $65 / 401(16.2 \%)$ & $30 / 298(10.1 \%)$ & \\
\hline Rheumatic & $4 / 401(1.0 \%)$ & $5 / 298(1.7 \%)$ & \\
\hline Other & $52 / 401(13.0 \%)$ & $21 / 298(7.0 \%)$ & \\
\hline \multicolumn{4}{|l|}{ Echocardiography } \\
\hline Ejection fraction $(\%)$ & $54.2 \pm 14.5$ & $56.0 \pm 11.5$ & .04 \\
\hline Severe MR & $442(97.4 \%)$ & $547(98.4 \%)$ & .3 \\
\hline Mild or greater TR & $252(55.9 \%)$ & $127(23.8 \%)$ & $<.001$ \\
\hline
\end{tabular}

Continuous variables are expressed as means \pm standard deviation. $B M I$, Body mass index; NYHA, New York Heart Association; $M R$, mitral regurgitation; $T R$, tricuspid regurgitation. minimally invasive procedure $(104 \pm 32$ minutes vs $82 \pm 31$ minutes $[P<.001]$ and $138 \pm 41$ minutes vs $107 \pm 37$ minutes $[P<.001]$, respectively, for the degenerative matched cohort; $101 \pm 32$ minutes vs $82 \pm 39$ minutes $[P<.001]$ and $137 \pm 42$ minutes vs $108 \pm 48$ minutes $[P<.001]$, respectively, for the overall matched cohort). Significant systolic anterior motion of the mitral valve was noted in 2 patients with mitral valve prolapse, both within the sternotomy group, and post-repair ejection fraction was comparable between groups. Within each matched subgroup analysis, patients undergoing minimally invasive mitral valve repair were more likely to have no residual post-repair MR $(97.4 \%$ vs $92.1 \%, P=.04$ for degenerative matched cohort; $95.5 \%$ vs $89.6 \%, P=.02$ for overall matched cohort), with the remainder exhibiting trace or mild post-repair MR. Of note, nonresectional leaflet remodeling and neochordae techniques were used more frequently in patients undergoing minimally invasive mitral valve repair. There was a higher incidence of bileaflet prolapse within the sternotomy group compared with the minimally invasive group in the overall matched analysis $(20.9 \%$ vs $11.4 \%, P=.03)$. Complete annuloplasty rings were used in nearly every patient, but flexible rings were implanted more often than semirigid rings for minimally invasive mitral valve repairs.

During the study interval, 272 patients underwent mitral valve replacement. Overall, 193 mitral replacements were performed via median sternotomy and 79 were performed via right minithoracotomy. Seventy-nine patients received a mitral valve prosthesis for mitral stenosis. The majority of the remaining patients underwent mitral valve replacement for endocarditis $(29.9 \%)$, rheumatic MR $(14.6 \%)$, severe mitral annular calcification $(13.1 \%)$, prosthetic failure $(10.9 \%)$, or ischemic cardiomyopathy $(4.0 \%)$, and were randomized to the mitral valve replacement cohort within the NHLBI Cardiothoracic Surgery Trials Network trial, 
TABLE 2. Demographics and clinical characteristics of patients undergoing mitral valve repair: Propensity-matched cohorts

\begin{tabular}{|c|c|c|c|c|c|c|}
\hline \multirow[b]{2}{*}{ Variable } & \multicolumn{3}{|c|}{ Any cause } & \multicolumn{3}{|c|}{ Degenerative only } \\
\hline & $\begin{array}{l}\text { Median sternotomy } \\
\quad(\mathrm{n}=\mathbf{2 0 1})\end{array}$ & $\begin{array}{l}\text { Minimally invasive } \\
(\mathbf{n}=201)\end{array}$ & $P$ value & $\begin{array}{l}\text { Median sternotomy } \\
\quad(\mathbf{n}=\mathbf{1 5 3})\end{array}$ & $\begin{array}{l}\text { Minimally invasive } \\
\quad(n=153)\end{array}$ & $P$ value \\
\hline \multicolumn{7}{|l|}{ Demographics } \\
\hline Age (y) & $57.0 \pm 12.8$ & $57.1 \pm 12.4$ & .9 & $57.1 \pm 12.8$ & $56.6 \pm 12.1$ & .7 \\
\hline Gender $(\%$ female $)$ & $71(35.5 \%)$ & $68(33.7 \%)$ & .8 & $57(37.3 \%)$ & $51(33.3 \%)$ & .6 \\
\hline BMI $\left(\mathrm{kg} / \mathrm{m}^{-2}\right)$ & $26.2 \pm 4.4$ & $26.2 \pm 4.3$ & 1.0 & $25.8 \pm 4.2$ & $25.8 \pm 4.2$ & .9 \\
\hline \multicolumn{7}{|l|}{ Comorbidities } \\
\hline Chronic kidney disease & $6(3.0 \%)$ & $6(3.0 \%)$ & 1.0 & $2(1.3 \%)$ & $2(1.3 \%)$ & 1.0 \\
\hline Hypertension & $95(47.5 \%)$ & $84(41.6 \%)$ & .3 & $61(39.9 \%)$ & $63(41.2 \%)$ & .9 \\
\hline Infective endocarditis & $18(9.0 \%)$ & $9(4.5 \%)$ & .08 & $7(4.6 \%)$ & $5(3.3 \%)$ & .8 \\
\hline Chronic lung disease & $20(10.0 \%)$ & $18(9.0 \%)$ & .7 & $12(7.8 \%)$ & $13(8.5 \%)$ & 1.0 \\
\hline Peripheral arterial disease & $2(1.0 \%)$ & $5(2.5 \%)$ & .5 & $0(0 \%)$ & $2(1.3 \%)$ & .5 \\
\hline Cerebrovascular disease & $14(7.0 \%)$ & $14(7.0 \%)$ & 1.0 & $8(5.3 \%)$ & $6(3.9 \%)$ & .6 \\
\hline Previous cardiac surgery & $16(8.0 \%)$ & $14(7.0 \%)$ & .7 & $8(5.3 \%)$ & $6(3.9 \%)$ & .6 \\
\hline NYHA functional class & & & .3 & & & .5 \\
\hline I & $58(28.9 \%)$ & $67(33.3 \%)$ & & $47(30.7 \%)$ & $53(34.6 \%)$ & \\
\hline II-IV & $143(71.1 \%)$ & $134(66.7 \%)$ & & $106(69.3 \%)$ & $100(65.4 \%)$ & \\
\hline Cause & & & .9 & & & 1.0 \\
\hline Degenerative & $156(77.6 \%)$ & $158(78.6 \%)$ & & $153(100.0 \%)$ & $153(100.0 \%)$ & \\
\hline Functional & $21(10.4 \%)$ & $21(10.4 \%)$ & & - & - & \\
\hline Other & $24(12.0 \%)$ & $22(8.5 \%)$ & & - & - & \\
\hline \multicolumn{7}{|l|}{ Echocardiography } \\
\hline Ejection fraction $(\%)$ & $56.7 \pm 11.9$ & $57.0 \pm 9.5$ & .8 & $58.1 \pm 9.3$ & $58.3 \pm 7.7$ & .8 \\
\hline Severe MR & $201(100.0 \%)$ & $201(100.0 \%)$ & .3 & $153(100.0 \%)$ & $153(100.0 \%)$ & 1.0 \\
\hline Moderate or greater TR & $39(19.4 \%)$ & $39(19.4 \%)$ & 1.0 & $31(20.3 \%)$ & $30(19.6 \%)$ & 1.0 \\
\hline Leaflet prolapse & & & .03 & & & .14 \\
\hline Anterior & $14(7.0 \%)$ & $14(7.0 \%)$ & & $10(6.5 \%)$ & $10(6.5 \%)$ & \\
\hline Posterior & $126(62.7 \%)$ & $144(71.6 \%)$ & & $104(68.0 \%)$ & $118(77.1 \%)$ & \\
\hline Bileaflet & $42(20.9 \%)$ & $23(11.4 \%)$ & & $39(25.5 \%)$ & $25(16.3 \%)$ & \\
\hline
\end{tabular}

Continuous variables are expressed as means \pm standard deviation. BMI, Body mass index; NYHA, New York Heart Association; MR, mitral regurgitation; TR, tricuspid regurgitation.

in which the University of Pennsylvania is a participant. Sixteen patients with degenerative MR received a mitral valve prosthesis; $25 \%$ were emergency procedures, and $50 \%$ of patients were more than 70 years of age. Seven patients underwent unsuccessful attempted mitral repair $(99 \%$ repair rate for degenerative MR), and a minimally invasive approach did not significantly increase the likelihood of a failed repair resulting in mitral valve replacement $(0.2 \%$ vs $1.0 \%, P=.1$, in the sternotomy and minimally invasive groups, respectively).

In-hospital outcomes are summarized in Table 4 . The incidence of postoperative hemorrhage requiring exploration did not differ between matched groups, yet transfusion was less frequent in patients who underwent minimally invasive surgery $(11.8 \%$ vs $20.3 \%, P=.04$ for the degenerative matched cohort; $14.0 \%$ vs $22.9 \%, P=.03$ for the overall matched cohort). Duration of postoperative ventilatory support and incidence of stroke, renal failure, sepsis, atrial fibrillation, and deep wound infection were similar between both matched groups. Length of intensive care unit stay, total hospital length of stay, and likelihood of discharge home were comparable between groups. However, in the overall matched cohort, patients undergoing the minimally invasive procedure were less likely to be readmitted within 30 days after discharge compared with patients undergoing conventional sternotomy $(4.4 \%$ vs $12.6 \%, P=.01)$. Hospital mortality rates did not significantly differ between the minimally invasive and sternotomy groups $(0 \%$ vs $0 \%$ for the degenerative matched cohort; $0 \%$ vs $0.5 \%$ $[\mathrm{n}=1], P=.5$ for the overall matched cohort).

Survival data are illustrated in Figures 2 and 3. Median follow-up was 4.2 years (interquartile range, 1.9-6.8). For matched patients with degenerative mitral valve disease, survival at 1,5 , and 9 years was $99 \%, 99 \%$, and $99 \%$, respectively, after minimally invasive surgery, and $99 \%, 97 \%$, and $95 \%$, respectively, after conventional sternotomy $(P=.8)$. In the overall matched population, 1-, 5-, and 9-year survival was $96 \%, 96 \%$, and $96 \%$, respectively, after minimally invasive mitral valve repair, and $97 \%, 92 \%$, and $89 \%$, respectively, after the conventional approach $(P=.8)$.

\section{DISCUSSION}

There is an increasing demand from patients and referring physicians for less-invasive mitral valve surgery. 
TABLE 3. Operative and echocardiographic data stratified by operative approach: Propensity-matched cohorts

\begin{tabular}{|c|c|c|c|c|c|c|}
\hline \multirow[b]{2}{*}{ Variable } & \multicolumn{3}{|c|}{ Any cause } & \multicolumn{3}{|c|}{ Degenerative only } \\
\hline & $\begin{array}{l}\text { Median sternotomy } \\
\quad(\mathbf{n}=\mathbf{2 0 1})\end{array}$ & $\begin{array}{l}\text { Minimally invasive } \\
\quad(\mathbf{n}=\mathbf{2 0 1})\end{array}$ & $P$ value & $\begin{array}{l}\text { Median sternotomy } \\
\qquad(\mathbf{n}=\mathbf{1 5 3})\end{array}$ & $\begin{array}{l}\text { Minimally invasive } \\
\quad(\mathbf{n}=\mathbf{1 5 3})\end{array}$ & $P$ value \\
\hline Crossclamp time (min) & $82.3 \pm 38.5$ & $101.3 \pm 32.4$ & $<.001$ & $81.9 \pm 30.7$ & $103.7 \pm 31.6$ & $<.001$ \\
\hline Bypass time (min) & $108.1 \pm 48.3$ & $136.8 \pm 42.0$ & $<.001$ & $106.8 \pm 36.8$ & $138.1 \pm 41.2$ & $<.001$ \\
\hline Repeat bypass run & $9(4.5 \%)$ & $6(3.0 \%)$ & .4 & $6(3.9 \%)$ & $5(3.3 \%)$ & .8 \\
\hline Significant SAM & $2(1.0 \%)$ & $0(0 \%)$ & .3 & $2(1.3 \%)$ & $0(0 \%)$ & .5 \\
\hline \multicolumn{7}{|l|}{ Ring type } \\
\hline Flexible & $14(7.0 \%)$ & $105(52.2 \%)$ & $<.001$ & $9(5.9 \%)$ & $90(58.8 \%)$ & $<.001$ \\
\hline Semirigid/rigid & $187(93.0 \%)$ & $96(47.8 \%)$ & & $144(94.1 \%)$ & $63(41.2 \%)$ & \\
\hline Incomplete & $5(2.5 \%)$ & $1(0.5 \%)$ & .1 & $0(0 \%)$ & $1(0.7 \%)$ & 1.0 \\
\hline Complete & $196(97.5 \%)$ & $200(99.5 \%)$ & & $153(100 \%)$ & $152(99.3 \%)$ & \\
\hline Repair strategy & & & $<.001$ & & & $<.001$ \\
\hline Leaflet resection & $136(67.7 \%)$ & $105(52.2 \%)$ & & $121(79.1 \%)$ & $98(64.1 \%)$ & \\
\hline Neochordae & $16(8.0 \%)$ & $37(18.4 \%)$ & & $15(9.8 \%)$ & $29(19.0 \%)$ & \\
\hline Leaflet remodeling & $15(7.5 \%)$ & $32(15.9 \%)$ & & $4(2.6 \%)$ & $19(12.4 \%)$ & \\
\hline Annuloplasty alone & $29(14.4 \%)$ & $19(9.5 \%)$ & & $10(6.5 \%)$ & $5(3.3 \%)$ & \\
\hline Post-repair MR & & & .04 & & & .04 \\
\hline None & $181(90.0 \%)$ & $192(95.5 \%)$ & & $140(92.1 \%)$ & $148(97.4 \%)$ & \\
\hline Trace/mild & $20(10.0 \%)$ & $9(4.5 \%)$ & & $12(7.9 \%)$ & $4(2.6 \%)$ & \\
\hline Moderate & $0(0 \%)$ & $0(0 \%)$ & & $0(0 \%)$ & $0(0 \%)$ & \\
\hline Post-repair EF (\%) & $57.8 \pm 14.2$ & $56.6 \pm 10.7$ & .3 & $58.4 \pm 12.0$ & $57.5 \pm 9.5$ & .5 \\
\hline
\end{tabular}

Continuous variables are expressed as means \pm standard deviation. $S A M$, Systolic anterior motion; $M R$, mitral regurgitation; $E F$, ejection fraction.

Minimally invasive approaches to the mitral valve are well described, with most surgeons using a lower hemisternotomy or right minithoracotomy to access the heart. Initial concerns focused on the greater risk of longer operations and peripheral cannulation at the expense of improved cosmesis. Yet, despite a paucity of objective evidence to assuage these concerns and demonstrate therapeutic equivalence, minimally invasive platforms for mitral valve surgery have been increasingly adopted. The recent consensus statement from the International Society of Minimally
Invasive Coronary Surgery assigned a class IIb recommendation for minimally invasive surgery for mitral valve disease. ${ }^{21}$ The present study affirms the noninferiority of minimally invasive mitral valve surgery via right minithoracotomy. Although procedure time is lengthened, risks are comparable or less, transfusions are less frequent, duration of ventilatory support is similar, hospital length of stay is equivalent, and long-term survival is similarly excellent.

Several reports have examined key outcomes after minimally invasive mitral valve surgery. ${ }^{22-24}$ As in the Society of

TABLE 4. In-hospital outcomes stratified by operative approach: Propensity-matched cohorts

\begin{tabular}{|c|c|c|c|c|c|c|}
\hline \multirow[b]{2}{*}{ Outcome } & \multicolumn{3}{|c|}{ Any cause } & \multicolumn{3}{|c|}{ Degenerative only } \\
\hline & $\begin{array}{l}\text { Median sternotomy } \\
\quad(\mathbf{n}=\mathbf{2 0 1})\end{array}$ & $\begin{array}{l}\text { Minimally invasive } \\
(n=201)\end{array}$ & $P$ value & $\begin{array}{l}\text { Median sternotomy } \\
\quad(\mathrm{n}=153)\end{array}$ & $\begin{array}{l}\text { Minimally invasive } \\
\quad(\mathbf{n}=\mathbf{1 5 3})\end{array}$ & $P$ value \\
\hline Death & $1(0.5 \%)$ & $0(0 \%)$ & .5 & $0(0 \%)$ & $0(0 \%)$ & - \\
\hline MI & $0(0 \%)$ & $1(0.5 \%)$ & .5 & $0(0 \%)$ & $1(0.7 \%)$ & 1.0 \\
\hline Deep infection & $0(0 \%)$ & $0(0 \%)$ & - & $0(0 \%)$ & $0(0 \%)$ & - \\
\hline Sepsis & $2(1.0 \%)$ & $0(0 \%)$ & .2 & $0(0 \%)$ & $0(0 \%)$ & - \\
\hline Stroke & $1(0.5 \%)$ & $0(0 \%)$ & .5 & $1(0.7 \%)$ & $0(0 \%)$ & 1.0 \\
\hline Renal failure & $3(1.5 \%)$ & $2(1.0 \%)$ & .7 & $1(0.7 \%)$ & $0(0 \%)$ & 1.0 \\
\hline Gastrointestinal event & $3(1.5 \%)$ & $0(0 \%)$ & .1 & $1(0.7 \%)$ & $0(0 \%)$ & 1.0 \\
\hline Exploration for hemorrhage & $1(0.5 \%)$ & $5(2.5 \%)$ & .2 & $1(0.7 \%)$ & $3(2.0 \%)$ & .4 \\
\hline Transfusion & $44(22.9 \%)$ & $28(14.0 \%)$ & .03 & $31(20.3 \%)$ & $18(11.8 \%)$ & .04 \\
\hline Atrial fibrillation & $50(25.0 \%)$ & $42(20.8 \%)$ & .3 & $34(22.2 \%)$ & $29(19.0 \%)$ & .6 \\
\hline Time to extubation (h) & $8.0(6.0-13.0)$ & $8.0(6.0-12.0)$ & .3 & $8.0(5.0-13.0)$ & $7.8(5.8-12.0)$ & .8 \\
\hline Time to discharge (d) & $6.0(5.0-8.0)$ & $6.0(5.0-7.0)$ & .4 & $6.0(5.0-7.0)$ & $6.0(5.0-7.0)$ & .9 \\
\hline Discharge home & $187(93.5 \%)$ & $193(95.5 \%)$ & .4 & $144(94.1 \%)$ & $149(97.4 \%)$ & .3 \\
\hline Readmission within $30 \mathrm{~d}$ & $15(12.6 \%)$ & $7(4.4 \%)$ & .01 & $8(5.2 \%)$ & $7(4.6 \%)$ & 1.0 \\
\hline
\end{tabular}

Continuous variables are expressed as medians with interquartile range. $M I$, Myocardial infarction. 


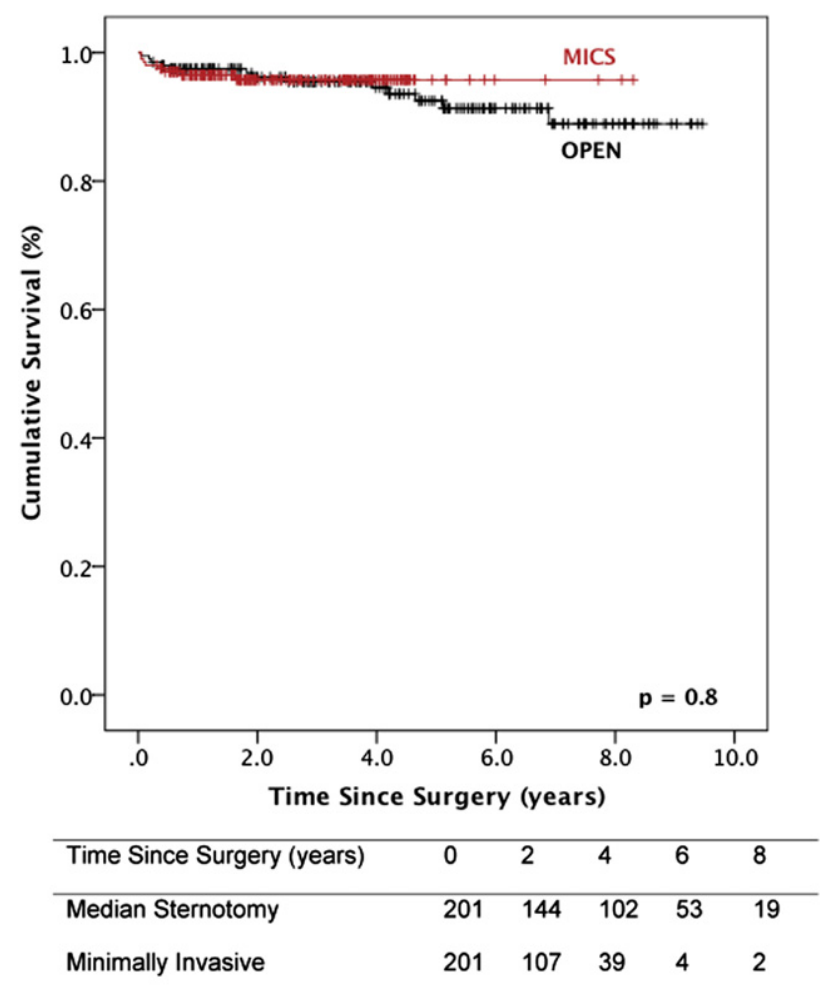

FIGURE 2. Survival after mitral valve repair stratified by operative approach: overall matched cohort. Numbers of patients at risk are included in the corresponding table. MICS, Minithoracotomy.

Thoracic Surgeons database entry guidelines, many investigators broadly define minimally invasive surgery as any procedure performed through less than a conventional median sternotomy. Nonetheless, the results of the metaanalyses to date are generally in accord. A meta-analysis by Modi and colleagues ${ }^{22}$ included 2827 patients and revealed lower rates of reoperation for postoperative hemorrhage, as well as a trend toward decreased hospital length of stay. Richardson and colleagues ${ }^{23}$ included 13 studies in their analysis and found that despite longer procedure times, minimally invasive mitral surgery was associated with reduced postoperative bleeding, faster times to extubation, less pain, and a more swift return to regular activity. Most recently, Cheng and colleagues ${ }^{24}$ examined the results of 35 studies ( 2 randomized, 33 nonrandomized) that excluded patients undergoing lower hemisternotomies from the minimally invasive group, but did include mitral valve replacements. A number of key outcomes were significantly improved with minimally invasive mitral valve surgery, including incidence of postoperative atrial fibrillation, postoperative bleeding and transfusion requirement, time to return to normal activity, and cosmetic indices of scar satisfaction. Despite longer procedure times, hospital length of stay and time to extubation were reduced. However, minimally invasive mitral valve surgery was not without risk.

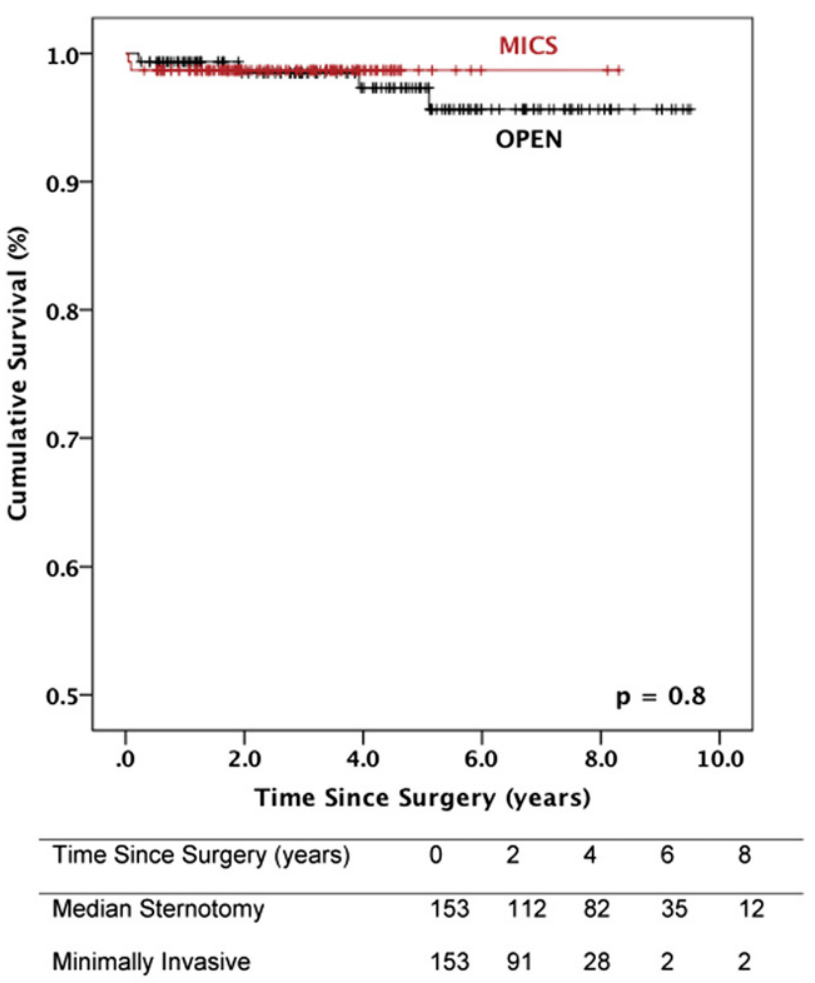

FIGURE 3. Survival after mitral valve repair stratified by operative approach: degenerative matched cohort. Numbers of patients at risk are included in the corresponding table. MICS, Minithoracotomy.

Rates of stroke ( $2.1 \%$ vs $1.2 \%)$, aortic dissection $(0.2 \%$ vs $0 \%$ ), groin complications ( $2 \%$ vs $0 \%$ ), and phrenic nerve palsy ( $3 \%$ vs $0 \%)$ were significantly increased.

Although rates of postoperative bleeding requiring reoperation were slightly higher numerically in our minimally invasive groups (although not significantly), transfusion requirements were significantly lower in the minimally invasive matched cohorts. This relationship is likely because these variables describe different types of bleeding. Exploration for postsurgical hemorrhage is typically related to an unnoticed or late arterial bleed, usually arising from a chest wall port site in patients undergoing minithoracotomy. On the other hand, blood product transfusions are related to overall blood loss. As proposed by Svensson and colleagues ${ }^{14}$ in their analysis of mitral valve surgery through a lower hemisternotomy approach, less overall blood loss is likely because of less extensive mediastinal dissection during minimally invasive surgery. Of note, overall rates of reoperation in our study were less than $1.5 \%$ and are among the lowest reported to date.

The benefit of minimally invasive approaches to mitral surgery on pulmonary function is contradictory. In the present study, duration of ventilator support was nearly equivalent between the minimally invasive and sternotomy groups. The study by Suri and colleagues ${ }^{13}$ is similar to 
our own and included a subset of patients from our health system. Although they found that port access was independently associated with a slightly decreased length of postoperative ventilatory support, the study population included patients from 2 reference centers. Within our health system, such a difference was not observed, and we agree that different postoperative management strategies between surgical teams likely account for the differences in time to extubation and discharge between published series.

All patients left the operating room with mild or less MR regardless of the surgical approach. Nevertheless, in both matched comparisons a minithoracotomy approach seemed to facilitate a more effective immediate repair. However, subsequent analysis revealed that a greater proportion of patients who underwent repair via median sternotomy had bileaflet prolapse, and repair techniques did differ between groups. This discrepancy may have contributed to the differences noted in post-repair MR. Yet, because the mitral valve lies in an annular plane that nearly approximates the sagittal plane of the body, a right lateral approach often provides a better en face view of the valve than median sternotomy. In addition, the feasibility of complex valve repair via a right lateral approach has been well described. ${ }^{25,26}$ It is important to note that a minimally invasive approach did not significantly increase the rate of a failed mitral valve repair resulting in replacement, and an overall repair rate of $99 \%$ was achieved in patients with degenerative mitral valve disease. Near $100 \%$ repair rates for mitral valve prolapse have recently been reported via sternotomy approaches. ${ }^{27}$

Although a number of series have reported trends toward shorter hospital stays in patients who undergo minimally invasive mitral valve surgery, ${ }^{15,24,28,29}$ we were unable to demonstrate such an effect. Shorter times to extubation and discharge result in lower hospital costs and less resource utilization, and are key arguments of robotic surgery advocates. Our data from the overall matched analysis do support a lower rate of early rehospitalization after surgery with a minimally invasive approach. This may have significant ramifications on cost analysis because readmissions are expensive, and Medicaid and Medicare no longer reimburse treatment of preventable events. However, because this trend was not observed in the degenerative cohort, the effect may be related to the pathology and not the procedure.

Observed differences in clinical outcomes between the minimally invasive and sternotomy groups in our study were negligible in a homogenous group of patients with degenerative mitral valve disease, as well as for all etiologies. Indices of postoperative morbidity and mortality were extremely low, and efficacy of repair and long-term survival were excellent in both matched groups. Our data add to that of other reference centers to support the noninferiority of minimally invasive mitral valve repair. ${ }^{8-10,13-15}$ Clearly, as in the case of all fledgling techniques, outcomes rely on operator experience. Yet, in our experience with isolated mitral valve disease of any cause, a right minithoracotomy or sternotomy approach may be used without compromising clinical outcome. Mortality rates less than $0.5 \%$, stroke rates less than $1 \%$, and reduction of MR to mild or less must be standards against which future percutaneous valve therapies are compared in average-risk surgical candidates. It is particularly important that outcomes are excellent in patients with degenerative mitral valve disease, because guidelines now recommend early surgery for asymptomatic patients with severe MR. ${ }^{19}$ Providing patients the option of a cosmetically favorable procedure without sacrificing efficacy and long-term durability will hopefully facilitate early surgical correction of MR before the development of left ventricular dysfunction.

\section{Study Limitations}

The limitations of the present study include its retrospective methodology. Treatment allocation bias certainly exists when comparing patients who underwent minimally invasive and conventional sternotomy approaches to mitral valve surgery. Patients selected for minimally invasive mitral surgery tend to be less sick, have fewer comorbidities and are often earlier in the course of their disease. Although propensity score matching helps account for such bias, it selects for patients of intermediate risk, because patients on either end of the probability spectrum are typically unmatchable. However, the distribution of propensity scores in our matched cohorts did closely approximate the distribution of propensity scores for the entire study population. Thus, a wide range of risk profiles was included in the present study to minimize limitations on generalizability. To our knowledge, this is the largest propensity score-matched comparison of mitral valve repair via right minithoracotomy and conventional sternotomy to date. Nevertheless, because the study population was derived from a single reference health system, external validity is partially limited at the expense of enhancing internal validity. Moreover, the data reported cannot be construed as equivalent to that of a large randomized controlled trial, which may be ethically infeasible.

\section{CONCLUSIONS}

Despite longer operative times, minimally invasive mitral valve repair affords no apparent disadvantages compared with valve repair via conventional sternotomy. In what we believe to be the largest propensity-matched analysis of isolated mitral valve repair via right minithoracotomy to date, we demonstrate in a health system-wide study that a minimally invasive approach facilitates at least equivalent mitral valve repair, with a near $100 \%$ repair rate, fewer transfusions, and lower early readmission rates. Ideally, the noninferiority of minimally invasive mitral valve repair may help improve referral rates of patients with MR before the 
development of adverse sequelae of the disease. In addition, the excellent results of minimally invasive mitral valve surgery should be used as the reference standard against which future percutaneous platforms for mitral valve surgery are compared.

\section{References}

1. Woo YJ, Seeburger J, Mohr FW. Minimally invasive valve surgery. Semin Thorac Cardiovasc Surg. 2007;19:289-98.

2. Schmitto JD, Mokashi SA, Cohn LH. Minimally-invasive valve surgery. J Am Coll Cardiol. 2010;56:455-62.

3. Woo YJ. Minimally invasive valve surgery. Surg Clin North Am. 2009;89: 923-49. $x$.

4. Padala M, Jimenez JH, Yoganathan AP, Chin A, Thourani VH. Transapical beating heart cardioscopy technique for off-pump visualization of heart valves. J Thorac Cardiovasc Surg. 2012;144:231-4.

5. Cosgrove DM 3rd, Sabik JF, Navia JL. Minimally invasive valve operations. Ann Thorac Surg. 1998;65:1535-9.

6. Cohn LH, Adams DH, Couper GS, et al. Minimally invasive cardiac valve surgery improves patient satisfaction while reducing costs of cardiac valve replacement and repair. Ann Surg. 1997;226:421-8.

7. Gammie JS, Bartlett ST, Griffith BP. Small-incision mitral valve repair: safe, durable, and approaching perfection. Ann Surg. 2009;250:409-15.

8. Seeburger J, Borger MA, Falk V, et al. Minimal invasive mitral valve repair for mitral regurgitation: results of 1339 consecutive patients. Eur J Cardiothorac Surg. 2008;34:760-5.

9. McClure RS, Cohn LH, Wiegerinck E, et al. Early and late outcomes in minimally invasive mitral valve repair: an eleven-year experience in 707 patients. J Thorac Cardiovasc Surg. 2009;137:70-5.

10. Modi P, Rodriguez E, Hargrove WC 3rd, Hassan A, Szeto WY, Chitwood WR Jr. Minimally invasive video-assisted mitral valve surgery: a 12-year, 2-center experience in 1178 patients. J Thorac Cardiovasc Surg. 2009;137:1481-7.

11. Grossi EA, Galloway AC, LaPietra A, et al. Minimally invasive mitral valve surgery: a 6-year experience with 714 patients. Ann Thorac Surg. 2002;74:660-4.

12. Lee S, Chang BC, Lim SH, Hong YS, Yoo KJ, Kang MS. Clinical results of minimally invasive open-heart surgery in patients with mitral valve disease: comparison of parasternal and low-sternal approach. Yonsei Med J. 2006;47:230-6.

13. Suri RM, Schaff HV, Meyer SR, Hargrove WC 3rd. Thoracoscopic versus open mitral valve repair: a propensity score analysis of early outcomes. Ann Thorac Surg. 2009;88:1185-90.

14. Svensson LG, Atik FA, Cosgrove DM, et al. Minimally invasive versus conventional mitral valve surgery: a propensity-matched comparison. J Thorac Cardiovasc Surg. 2010;139:926-32. e921-2.

15. Iribarne A, Russo MJ, Easterwood R, et al. Minimally invasive versus sternotomy approach for mitral valve surgery: a propensity analysis. Ann Thorac Surg. 2010; 90:1471-8.
16. Iribarne A, Easterwood R, Russo MJ, et al. A minimally invasive approach is more cost-effective than a traditional sternotomy approach for mitral valve surgery. J Thorac Cardiovasc Surg. 2011;142:1507-14.

17. Atik FA, Svensson LG, Blackstone EH, Gillinov AM, Rajeswaran J, Lytle BW Less invasive versus conventional double-valve surgery: a propensity-matched comparison. J Thorac Cardiovasc Surg. 2011;141:1461-8. e1464.

18. Enriquez-Sarano M, Avierinos JF, Messika-Zeitoun D, et al. Quantitative determinants of the outcome of asymptomatic mitral regurgitation. $N$ Engl J Med. 2005;352:875-83.

19. Bonow RO, Carabello BA, Chatterjee K, et al. 2008 Focused update incorporated into the ACC/AHA 2006 guidelines for the management of patients with valvular heart disease: a report of the American College of Cardiology/American Heart Association Task Force on Practice Guidelines (Writing Committee to Revise the 1998 Guidelines for the Management of Patients With Valvular Heart Disease): endorsed by the Society of Cardiovascular Anesthesiologists, Society for Cardiovascular Angiography and Interventions, and Society of Thoracic Surgeons. Circulation. 2008;118: e523-661.

20. Casselman FP, Van Slycke S, Dom H, Lambrechts DL, Vermeulen Y, Vanermen H. Endoscopic mitral valve repair: feasible, reproducible, and durable. J Thorac Cardiovasc Surg. 2003;125:273-82.

21. Falk V, Cheng DC, Martin J, et al. Minimally invasive versus open mitral valve surgery: a consensus statement of the international society of minimally invasive coronary surgery (ISMICS) 2010. Innovations. 2010;6:66-76.

22. Modi P, Hassan A, Chitwood WR Jr. Minimally invasive mitral valve surgery: a systematic review and meta-analysis. Eur J Cardiothorac Surg. 2008;34 943-52.

23. Richardson $L$, Richardson $M$, Hunter $S$. Is a port-access mitral valve repair superior to the sternotomy approach in accelerating postoperative recovery? Interact Cardiovasc Thorac Surg. 2008;7:678-83.

24. Cheng DC, Martin J, Lal A, et al. Minimally invasive versus conventional open mitral valve surgery: a meta-analysis and systematic review. Innovations. 2011;6: 84-103.

25. Woo YJ, MacArthur JW Jr. Simplified nonresectional leaflet remodeling mitra valve repair for degenerative mitral regurgitation. J Thorac Cardiovasc Surg. 2012;143:749-53.

26. Woo YJ, MacArthur JW Jr. Posterior ventricular anchoring neochordal repair of degenerative mitral regurgitation efficiently remodels and repositions posterior leaflet prolapse. Eur J Cardiothorac Surg. (In press).

27. Castillo JG, Anyanwu AC, Fuster V, Adams DH. A near $100 \%$ repair rate for mitral valve prolapse is achievable in a reference center: implications for future guidelines. J Thorac Cardiovasc Surg. 2012;144:308-12.

28. Woo YJ, Nacke EA. Robotic minimally invasive mitral valve reconstruction yields less blood product transfusion and shorter length of stay. Surgery. 2006; 140:263-7.

29. Gaudiani VA, Grunkemeier GL, Castro LJ, Fisher AL, Wu Y. Mitral valve operations through standard and smaller incisions. Heart Surg Forum. 2004;7: E337-42. 
APPENDIX 1. Multivariable logistic regression to model a dichotomous outcome of minimally invasive or open repair: Overall analysis

\begin{tabular}{|c|c|c|c|c|}
\hline Variable & Coefficient B & OR* & $95 \% \mathrm{CI}$ & $P$ value \\
\hline Age & 0.007 & 1.01 & $(0.99-1.02)$ & .4 \\
\hline \multicolumn{5}{|l|}{ BMI (vs $>30 \mathrm{~kg} / \mathrm{m}^{-2}$ ) } \\
\hline Underweight $\left(<18.5 \mathrm{~kg} / \mathrm{m}^{-2}\right)$ & 0.446 & 2.21 & $(0.54-9.01)$ & .4 \\
\hline Normal $\left(18.5-25 \mathrm{~kg} / \mathrm{m}^{-2}\right)$ & -0.189 & 1.18 & $(0.69-1.99)$ & .4 \\
\hline Overweight $\left(>25 \mathrm{~kg} / \mathrm{m}^{-2}\right)$ & 0.088 & 1.55 & $(0.92-2.61)$ & .7 \\
\hline Female gender & 0.081 & 1.18 & $(0.79-1.74)$ & .4 \\
\hline NYHA functional class I & 0.207 & 1.51 & $(1.01-2.27)$ & .05 \\
\hline Degenerative cause & -0.033 & 0.94 & $(0.53-1.64)$ & .8 \\
\hline Chronic lung disease & 0.129 & 1.29 & $(0.69-2.42)$ & .4 \\
\hline Severe MR & 0.525 & 2.86 & $(1.16-7.06)$ & .02 \\
\hline Greater than mild tricuspid regurgitation & -0.694 & 0.25 & $(0.16-0.39)$ & $<.001$ \\
\hline Ejection fraction $(\%)$ & 0.009 & 1.01 & $(0.99-1.03)$ & .3 \\
\hline Previous cardiac intervention & 0.021 & 1.04 & $(0.54-2.00)$ & .9 \\
\hline Type II MR & 0.353 & 2.02 & $(0.93-4.40)$ & .07 \\
\hline Intercept & -1.989 & & & \\
\hline
\end{tabular}

OR, Odds ratio; $C I$, confidence interval; $B M I$, body mass index; $N Y H A$, New York Heart Association; $M R$, mitral regurgitation. *OR represents minimally invasive sternotomy. $c$-statistic 0.71 ; median difference in propensity scores of matched pairs 0.0015 (interquartile range, $0.0005-0.008$ ).

APPENDIX 2. Multivariable logistic regression to model a dichotomous outcome of minimally invasive or open repair: Degenerative cause analysis

\begin{tabular}{|c|c|c|c|c|}
\hline Variable & Coefficient B & OR* & $95 \% \mathbf{C I}$ & $P$ value \\
\hline Age & 0.007 & 1.01 & $(0.99-1.03)$ & .4 \\
\hline \multicolumn{5}{|l|}{ BMI (vs $>30 \mathrm{~kg} / \mathrm{m}^{-2}$ ) } \\
\hline Underweight $\left(<18.5 \mathrm{~kg} / \mathrm{m}^{-2}\right)$ & 0.085 & 1.53 & $(0.28-8.46)$ & .9 \\
\hline Normal $\left(18.5-25 \mathrm{~kg} / \mathrm{m}^{-2}\right)$ & -0.034 & 1.36 & $(0.72-2.55)$ & .9 \\
\hline Overweight $\left(>25 \mathrm{~kg} / \mathrm{m}^{-2}\right.$ ) & 0.287 & 1.87 & $(1.0-3.51)$ & .3 \\
\hline Female gender & 0.073 & 1.16 & $(0.74-1.82)$ & .5 \\
\hline NYHA functional class I & 0.277 & 1.74 & $(1.11-2.74)$ & .02 \\
\hline Chronic lung disease & 0.284 & 1.77 & $(0.83-2.74)$ & .1 \\
\hline Severe MR & 0.540 & 2.94 & $(0.75-11.51)$ & .1 \\
\hline Greater than mild tricuspid regurgitation & -0.661 & 0.27 & $(0.16-0.44)$ & $<.001$ \\
\hline Ejection fraction $(\%)$ & -0.001 & 1.00 & $(0.98-1.02)$ & .9 \\
\hline Previous cardiac intervention & -0.167 & 0.72 & $(0.28-1.84)$ & .5 \\
\hline Intercept & -1.270 & & & \\
\hline
\end{tabular}

